\title{
Reversed-Phase Liquid Chromatography
}

National Cancer Institute

\section{Source}

National Cancer Institute. Reversed-Phase Liquid Chromatography. NCI Thesaurus. Code C161770.

A form of high performance liquid chromatography where the stationary phase is hydrophobic.Hydrophilic molecules in the sample will absorb to the stationary phase and can be shifted to the mobile phase through the use of an increasingly polar solvent gradient. 